\title{
RECONCILIANDO LA TORMENTOSA RELACIÓN ENTRE EL DERECHO CONSTITUCIONAL Y EL DERECHO EUROPEO: EL RESPETO POR LA IDENTIDAD NACIONAL BAJO EL TRATADO DE LISBOA
}

\author{
Stephan W. Schill, Heidelberg*
}

\section{INTRODUCCIÓN}

La relación entre el ordenamiento legal de la Unión Europea (UE) y el ordenamiento constitucional de los Estados Miembros de la UE, así como también la relación entre los "custodios" de los órdenes constitucionales, esto es, el Tribunal de Justicia de la Unión Europea (TJUE) y los tribunales constitucionales domésticos, están entre los problemas teóricos y doctrinarios más desafiantes en el espacio legal Europeo. Dos perspectivas chocan en este contexto. La TJUE sostiene una doctrina de primacía absoluta del régimen legal de la UE sobre todo el derecho de los Estados Miembros, incluyendo el orden constitucional. Así, el Tribunal, en su significativa decisión en Costa v. ENEL estableció el principio de primacía del derecho Europeo en relación al derecho doméstico de los Estados Miembros, ${ }^{1}$ principio que extendió en numerosas decisiones siguientes también al derecho constitucional nacional. ${ }^{2}$ Por ejemplo, Alemania fue obligada a modificar su Constitución, que impedía a las mujeres de servir en el ejército alemán, porque esta discriminación sexual en materia de empleo era contraria a una directiva de la UE. ${ }^{3}$

Los tribunales constitucionales de los Estados Miembros, en contraste, sostienen reservas legales constitucionales en relación a la primacía del derecho de la UE. En la famosa decisión Solange I de 1974, por ejemplo, el Tribunal Constitucional Federal Alemán (Bundesverfassungsgericht) estableció que controlaría si el derecho europeo estuviera conforme a los derechos fundamentales consagrados en la Constitución alemana. ${ }^{4}$ Pese a que modificó esta posición en la decisión Solange $I{ }^{5}$, continuó formulando reservas constitucionales frente a la primacía del derecho europeo. ${ }^{6}$ Otros tribunales constitucionales europeos applican reservas legales de una manera similar. ${ }^{7}$

De una perspectiva tradicional de la relación entre sistemas legales que está modelada bajo categorías jerárquicas tales conflictos pueden ser dañinos para la efectividad del derecho europeo y suscitar cuestionamientos de la unidad legal de la UE. Asimismo, propicia cierta tormentosa relación entre los tribunales constitucionales domésticos y la TJUE. Sin embargo, investigaciones recientes, sugieren que los modelos jerárquicos no describen de manera adecuada la situación legal en Europa. Por lo contrario, la relación entre el derecho europeo y el derecho constitucional nacional se captura de forma más convincente con visiones más pluralistas del orden constitucional.

Esto explica el éxito del concepto de red y - sobre todo en Alemania del concepto de Verbund (estructura compuesta) para capturar la relación entre el derecho europeo y el derecho constitucional dómestico. ${ }^{8}$ Significa que se concibe los ordenamientos constitucionales de los Estados Miembros y el derecho europeo como parte de un solo orden constitucional, una Constitución compuesta, y a la TJUE y a los tribunales constitucionales nacionales, como parte de una jurisdicción constitucional compuesta. ${ }^{9}$ Se base en la observación 
que el ejercicio de autoridad pública en Europa hoy no es, y ya no puede ser, ni doméstico ni supranacional. En cambio, lo nacional y lo supranacional deben ser vistos unidos de forma inseparable con actores que cooperan, pero también se friccionan. ${ }^{10}$ El concepto de una constitución compuesta y el entendimiento del TJUE y de los tribunales constitucionales domésticos como parte de una jurisdiccion compuesta pueded superar las perspectivas jerárquicas en cuanto a la relación del derecho europeo y el derecho constitucional nacional.

El concepto de una constitución compuesta resuena en un número de disposiciones en el derecho positivo. Ejemplos se encuentran a nivel nacional en las cláusulas de salvaguardas estructurales, como el Artículo 23, párrafo 1 de la Constitución alemana, y a nivel de la UE, por ejemplo en el Artículo 7 TUE. También resuena en el Artículo 4, párrafo 2 TUE que refiere al deber de la UE de respetar la identidad nacional de los Estados Miembros. Dispone:

"La Unión respetará la igualdad de los Estados miembros ante los Tratados, así como su identidad nacional, inherente a las estructuras fundamentales políticas y constitucionales de éstos, también en lo referente a la autonomía local y regional. Respetará las funciones esenciales del Estado, especialmente las que tienen por objeto garantizar su integridad territorial, mantener el orden público y salvaguardar la seguridad nacional. En particular, la seguridad nacional seguirá siendo responsabilidad exclusiva de cada Estado miembro."

Esta disposición remonta a otra norma que existía en el Tratado de Maastricht que simplemente señalaba: "la Unión respeta la identidad nacional de sus Estados Miembros." Sin embargo, esta norma no fue objeto de la jurisdicción de la TJUE y no jugó un rol importante en su jurisprudencia. ${ }^{11}$

El Tratado de Lisboa, en contraste, hoy aumenta la importancia de la "cláusula de identidad", tanto institucionalmente como en sustancia. Primero, el Artículo 4, párrafo 2 TUE ahora se encuentra bajo la jurisdicción del TJUE; segundo, la noción de identidad nacional está ahora vinculada a "las estructuras políticas y constitucionales fundamentales" de los Estados Miembros. Esta disposición, agregaré, ratifica y justifica hasta cierto punto la jurisprudencia de los tribunales constitucionales de los Estados Miembros en cuanto a las reservas frente a la primacía absoluta del derecho de la UE. ${ }^{12} \mathrm{Al}$ mismo tiempo, el Artículo 4, párrafo 2 TUE, propondré, también intenta abarcar la facultad de hacer uso de tales reservas constitucionales relativas a la jurisdicción de la TJUE. De ese modo, entonces, constitucionaliza la cuestión de la relación entre el derecho europeo y el derecho constitucional nacional y requiere que el TJUE y los tribunales constitucionales dómesticos cooperen para implementar una constitución compuesta. Asi, el respeto para la identidad nacional puede ayudar a reconciliar la tormentosa relación entre el derecho europea y el derecho constitucional nacional.

Este artículo procederé de la siguiente manera: primero, describe el Artículo 4, párrafo 2 TUE como una puerta de entrada que permite al derecho constitucional nacional de enfiltrar en el ordenamiento constitucional europeo; segundo, aborda la pregunta de qué tipo de disposiciones constitucionales 
forman parte de la identidad nacional de los Estados Miembros; y finalmente, centra en las consecuencias legales de la obligacion de respetar la identidad nacional y la implementación procedimental por el TJUE y los tribunales constitucionales nacionales. Esta implementación debe ser regida por el principio de cooperación leal (Artículo 4, párrafo 3 TUE).

\section{ARTICULO 4, PÁRRAFO 2 TUE COMO PUERTA DE ENTRADA PARA EL DERECHO CONSTITUCIONAL DE LOS ESTADOS MIEMBROS}

\section{La jurisprudencia del TJUE en cuanto a la identidad nacional}

Aunque previo al Tratado de Lisboa la cláusula de identidad no se encontraba dentro de la jurisdicción de la TJUE, el Tribunal ya había hecho uso de la noción de "identidad nacional." Jugaba un rol, aunque menor, en el aserto relativo a si restricciones de las libertades fundamentales de la UE por medidas de los Estados Miembros podían justificarse. Así, en un caso surgió la pregunta de si Luxemburgo podía restringir el acceso al empleo en el sistema de educación pública a sus nacionales, como lo requería la Constitución del país. EI TJUE observó que "la salvaguardia de la identidad nacional de los Estados miembros constituye un objetivo legítimo y respetado por el ordenamiento jurídico comunitario (tal como reconoce, por otra parte, el apartado 1 del artículo F del Tratado de la Unión Europea)", que, en princípio puede justifica la restricción de las libertades fundamentales. ${ }^{13}$ Sin embargo, en el caso en cuestión, el Tribunal determinó que la restricción era desproporcionada. ${ }^{14}$ En otros contextos, en contraste, el TJUE aceptó que varios principios constitucionales podrían servir como una justificación a la restricción de libertades fundamentales, incluyendo la libertad de reunión y de expresión, ${ }^{15}$ dignidad humana, ${ }^{16}$ libertad de asociación, ${ }^{17}$ la diversidad de los medios ${ }^{18}$ y la protección de menores. ${ }^{19}$ Mostrar resguardo por el derecho constitucional nacional no es, entonces, ajeno al TJUE.

\section{El contexto sistemático: articulo 4 TUE y la estructura federal de la Unión}

Una aproximación a la comprensión de la cláusula de la identidad también necesita tomar en consideración su contexto. Está incorporado en el Artículo 4 TUE, que en sus tres párrafos establece cinco principios para la relación entre la UE y sus Estados Miembros. Circunscribe las bases de una estructura federal, pero no jerárquica. Se basa en la doble perspectiva donde los Estados Miembros dependen de la UE para perseguir políticas públicas comunes efectivas a nivel supranacional, pero donde también la UE depende, a su vez, de Estados Miembros legítimos y efectivos que participen en la creación del derecho europeo y puedan, consecuentemente, implementarlo. De ese modo, el Artículo 4, párrafo 1 TUE instaura el principio de competencia limitada y derivada de la UE. Clarifica que los Estados Miembros son entidades genuinas y autónomas ejerciendo poder. El Artículo 4, párrafo 3 TUE contiene el principio de cooperación leal entre la Unión y los Estados Miembros. El Artículo 4, párrafo 2 TUE establece tres principios más: la cláusula de identidad, el principio de igualdad de los Estados Miembros y contiene además, una garantía para las funciones Estatales. 
La cláusula de identidad tiene una significación específica en este contexto, porque refleja la voluntad de los Estados Miembros de resguardarse a sí mismos frente a la Unión. No obstante, el hecho de que la terminología refiera al respeto por la identidad nacional, y no a la soberanía del Estado, ya demuestra la profundidad alcanzada en la integración Europea y la transformación fundamental que tiene lugar cuando un Estado se convierte en Estado Miembro de la UE. ${ }^{20}$ A pesar de la ambigüedad de la noción de identidad nacional, no hay duda que en ella se incluye mucho menos que en el tradicional concepto de soberanía proveniente del derecho internacional y constitucional, el cual es entendido como el poder comprensivo del Estado para gobernar tanto externa como internamente. ${ }^{21}$

El respeto a la igualdad de los Estados Miembros antes de los Tratados y el respeto por las funciones fundamentales del Estado han sido insertados novedosamente en el Tratado de Lisboa. ${ }^{22}$ Su propósito era el de dejar claro que la Unión debía respetar ciertas competencias esenciales de los Estados Miembros. No obstante, en lugar de hacer un listado de las materias que no podían ser transferidas a la UE, los redactores se inclinaron por un concepto más flexible como el de identidad nacional, en razón de que un listado de competencias podría dar la impresión que el ejercicio de la autoridad por los Estados Miembros requeriría justificación ante la UE. ${ }^{23}$ La cláusula de igualdad en el Artículo 4, párrafo 2 TUE es un elemento importante del pluralismo constitucional europeo, dada la diversidad de las tradiciones constitucionales de los Estados Miembros. Es esa variedad de tradiciones y valores constitucionales que también forma el contexto de la cláusula de identidad.

\section{Orientación constitucional de la cláusula de identidad}

La diferencia textual más grande entre la cláusula de identidad en el Tratado de Lisboa y su predecesora en los Tratados de Ámsterdam y Maastricht está dado por el vínculo de la identidad nacional con las "estructuras fundamentales políticas y constitucionales." Esto impide a la noción de identidad nacional centrarse en diferencias culturales y de lenguaje, ${ }^{24}$ y en su lugar vuelve al criterio de los órdenes constitucionales de los Estados Miembros como el aspecto central. De esa forma, la identidad nacional bajo el Tratado de Lisboa es entendida en términos de los valores constitucionales de los Estados Miembros. El Artículo 4, párrafo 2 TUE es Derecho de la Unión, por tanto, provee una base textual para delinear un enlace conciso y legalmente relevante entre el derecho constitucional nacional y el Derecho de la UE.

El concepto de identidad nacional del Artículo 4, párrafo 2 TUE no determina lo qué es la identidad nacional de cada uno de los Estados Miembros. Sin embargo, al emplear las palabras "estructuras fundamentales políticas y constitucionales de éstos, también en lo referente a la autonomía local y regional" establece un marco para lo que pudiera caer bajo el ámbito del Artículo 4, párrafo 2 TUE. ${ }^{25}$ Desde la perspectiva del derecho europeo, entonces, sólo lo que se encuentra consagrado en la Constitución Nacional o en los procesos constitucionales de los Estados Miembros puede ser relevante para la identidad nacional en el sentido del Artículo 4, párrafo 2 TUE. 
Más aún, no toda peculiaridad constitucional local puede ser considerada como parte de la identidad nacional de un Estado Miembro dentro del significado del Artículo 4, párrafo 2 TUE. Las expresiones señaladas indican que solamente estructuras constitucionales fundamentales de los Estados Miembros son relevantes. ${ }^{26}$ En consecuencia, no toda disposición constitucional se encuentra protegida bajo el Artículo 4, párrafo 2 TUE. De otro modo, prácticamente toda cuestión se volvería en una cuestión de identidad nacional si consideramos, por ejemplo, que en Alemania casi toda cuestión política se cierne sobre derechos y libertades establecidas en la Constitución. El ámbito del Artículo 4, párrafo 2 TUE debe entonces quedar limitado a conflictos específicamente intensos. No es necesario, sin embargo, que un principio constitucional considerado por un Estado Miembro como parte de su identidad nacional, sea igualmente visto como una disposición central en las constituciones de los Estados Miembros. ${ }^{27}$

En consecuencia, el Artículo 4, párrafo 2 TUE puede ser considerado como una puerta de entrada que abre el derecho de la UE hacia el derecho constitucional nacional. De ese modo, el Artículo 4, párrafo 2 TUE, en principio, debe ser interpretado a la luz de lo que el Derecho Constitucional de cada Estado Miembro define como parte de su respectiva identidad nacional.

\section{CONTENIDO RELEVANTE DEL DERECHO CONSTITUCIONAL DE LOS ESTADOS MIEMBROS}

\section{Disposiciones constitucionales}

Aunque el Artículo 4, párrafo 2 TUE constituye una norma de la UE, se refiere el intérprete al derecho constitucional nacional. Pero, no todas las disposiciones del derecho constitucional pueden ser relevantes. De particular importancia, sin embargo, son las disposiciones constitucionales que impiden al legislador de realizar ciertos cambios constitucionales, tales como el Artículo 79, párrafo 3 de la Constitución alemana, Art. 197 de la Constitución Belga, Art. 89, párrafo 5 de la Constitución francesa, etc., o que sujetan las enmiendas constitucionales a procedimientos dificultosos, como el Art. 168 de la Constitución española. El profundo afianzamiento constitucional sugiere que el contenido protegido es parte de la identidad nacional del Estado Miembro involucrado.

Así se destaca, desde la perspectiva del derecho constitucional comparado, un vasto grado de congruencia en las materias de derecho constitucional nacional a las cuales cada país otorga relevancia especial. Consecuencia de lo anterior, los valores sujetos a una protección constitucional especial forman parte de las siguientes categorías:

1. La protección de principios básicos de organización del Estado (tales como federalismo, formas de gobierno republicano, formas de gobierno monárquica);

2. Soberanía estatal y el principio de democracia; 
3. Emblemas del Estado (por ejemplo, bandera);

4. Finalidades del Estado; y

5. La protección de la dignidad humana, derechos fundamentales y el imperio de la ley. ${ }^{28}$

Sin embargo, algunas Constituciones también contienen reglas muy específicas, sino idiosincráticas, que están protegidas frente a enmiendas constitucionales. El Artículo 4, párrafo 7 de la Constitución griega, por ejemplo, prohíbe al Estado otorgar a los ciudadanos títulos nobiliarios o de rango. No obstante, el núcleo común de todas las diferentes reglas constitucionales en cuestión es un reconocimiento del constitucionalismo. ${ }^{29}$

Dicho reconocimiento, así como los principios protegidos específicamente por la Constitución de cada país, también están reflejados en el Artículo 2 TUE. Como la UE y sus Estados Miembros comparten un marco legal y político-ideológico que legitima y limita el ejercicio del poder público, no se puede sino notar una convergencia de gran alcance entre el derecho constitucional nacional y el ordenamiento legal de la UE. Conflictos en torno al respeto de la identidad nacional serán pues, un fenómeno excepcional. El desarrollo actual y el hecho que el conflicto jurisprudencial entre el TJUE y los tribunales constitucionales de los países relativo a la primacía del derecho constitucional europeo o nacional era hasta ahora teórico, esencialmente confirma esto.

\section{nacionales \\ 2. Reservas constitucionales desarolladas por los tribunales}

Las disposiciones de las constituciones nacionales, sin embargo, sólo dan una primera indicación del significado de la identidad nacional desde la perspectiva de los Estados Miembros. Es necesario observar la jurisprudencia de los tribunales constitucionales y cortes supremas nacionales. En este contexto, las decisiones respecto a la relación entre el derecho europeo y el derecho constitucional juega un rol crucial, ya que tratan casos específicos de conflicto actual o eventual, y muestran el lugar en donde los tribunales de los Estados Miembros trazan la línea para protegerse de una Unión cada vez más cercana.

Aun en este ámbito, se puede observar una convergencia en la jurisprudencia de las Cortes de los Estados Miembros. ${ }^{30}$ Así, por un lado, con algunas excepciones, ${ }^{31}$ los tribunales constitucionales y cortes supremas, reconocen, en principio, la primacía del derecho de la UE sobre el derecho nacional; por otro lado, la mayoría han desarrollado ciertas reservas constitucionales y sostienen tener la palabra final acerca de la relación entre el derecho europeo y el derecho constitucional nacional. Tales avances han tenido lugar desde la década de los años 1970, primero en Italia ${ }^{32}$ y Alemania, ${ }^{33}$ luego también en Irlanda, ${ }^{34}$ Dinamarca, ${ }^{35}$ España, ${ }^{36}$ Francia, $^{37}$ Hungría ${ }^{38}$ y la República Checa. ${ }^{39}$ Pero aún en los Estados Miembros cuyas tribunales constitucionales consideran al derecho constitucional generalmente superior, como en Polonia, se pueden apreciar tendencias en el sentido de que el control realizado por el tribunal constitucional respecto a las normas de la UE 
es muy limitado; en cambio, aún estos tribunales, conceden que la TJUE asuma un rol primordial en el control de legalidad del orden europeo. ${ }^{40} \mathrm{~A}$ pesar de que los puntos de partida de cada enfoque son conceptualmente distintos, ambos conducen finalmente a resultados similares, esto es, el reconocimiento de la primacía del derecho europeo y la invocación de reservas constitucionales.

\section{Contenido de las reservas constitucionales}

En cuanto al contenido, las reservas desarrolladas por la jurisprudencia de los tribunales constitucionales regularmente se ocupan del requisito de que la UE ejerza su poder de conformidad a los principios constitucionales fundamentales estructurales, particularmente la persistencia de la existencia de los Estados Miembros como estados, ${ }^{41}$ el principio de federalismo, ${ }^{42}$ componentes clave del estado de derecho, ${ }^{43}$ el principio democrático, ${ }^{44}$ y el contenido esencial de los derechos fundamentales. ${ }^{45}$ Estos principios suelen coincidir con las disposiciones constitucionales mencionadas antes, que establecen un núcleo en las respectivas constituciones que no puede ser modificado, o bien serlo, pero con dificultad.

En cuanto a la formulación de reservas constitutcionales que se encuentran en desarrollo, la mayoría de los tribunales constitucionales se han limitado simplemente a declarar que los actos de la UE no pueden vulnerar principios constitucionales, sin establecer con claridad como esos principios constitucionales fundamentales se relacionan con específicas áreas politicas 0 legales. Un ejemplo típico lo demuestra la jurisprudencia del Tribunal Constitucional de Italia. Determinó el estándar constitucional a emplear frente a las reservas simplemente como "los principios fundamentales de nuestro orden constitucional 0 los derechos humanos inalienables." ${ }^{46}$ Varios tribunales constitucionales y cortes supremas también dejan claro que apartiene al proceso político de los Estados Miembros determinar los límites de la integración Europea y no a los tribunales. ${ }^{47}$

A pesar de ello, algunos detalles específicos de lo que cae bajo las disposiciones centrales del derecho constitucional nacional desde la perspectiva de los tribunales constitucionales domésticos, pueden ser deducidos a partir de la jurisprudencia constitucional. El Tribunal Constitucional Checo, por ejemplo, consideró la protección de minorías nacionales y grupos étnicos, el principio de no-discriminación y la libre competencia entre partidos políticos sin recurrir a la violencia, como parte del núcleo sustantivo de la Constitución Checa. ${ }^{48}$ Como una mayor concreción del concepto de Estado de Derecho, varios tribunales han mencionado: el principio de certeza legal, ${ }^{49}$ acceso a los tribunales para la revisión de medidas tomadas por el gobierno, ${ }^{50}$ el principio de proporcionalidad, ${ }^{51}$ la prohibición de leyes retroactivas, ${ }^{52}$ y la obligación de motivar las decisiones tomadas por la administración. ${ }^{53}$

Para el Tribunal Constitucional Federal Alemán, la protección de la identidad nacional abarca la protección de derechos fundamentales ${ }^{54}$ y la salvaguarda del fundamento democrático del Estado. ${ }^{55}$ Haciendo referencia al Artículo 4, párrafo 2 TUE, considera que la identidad nacional de Alemania se 
define por las barreras de la llamada "cláusula de eternidad" del Artículo 79, párrafo 3 de la Constitución alemana. ${ }^{56}$ Esta cláusula previene al legislador de realizar ciertas modificaciones a la constitución, incluido el principio democrático, el concepto de Estado de Derecho, el concepto de Estado de bienestar, la forma republicana de gobierno, la estructura federal de Alemania, y el respeto por la dignidad humana y las características esenciales de los derechos fundamentales básicos. ${ }^{57}$

El Tribunal Constitucional Federal Alemán, sin embargo, llega demasiado lejos al determinar el alcance de la identidad nacional cuando señala que su protección requiere que se deje "suficiente espacio a los Estados Miembros para la formación política de las condiciones económicas, culturales y de convivencia social." ${ }^{58}$ Esto, continua el Tribunal, "se aplica en particular en aquellas áreas que modelan las condiciones de vida de los ciudadanos, en particular la esfera privada de su propia responsabilidad y de la seguridad política y social, protegida por los derechos fundamentales, así como también a las decisiones políticas que dependen especialmente de percepciones culturales, históricas y lingüísticas y que se desarrollan en el discurso público dentro de la esfera de las políticas públicas y parlamentaria." ${ }^{29}$

Más aún, para el Tribunal Constitucional Alemán, “áreas esenciales de acción democrática formativa incluyen, inter alia, ciudadanía, el monopolio civil y militar del uso de la fuerza, ingresos y gastos, incluyendo financiamiento externo y todos los elementos de apropiación que son decisivos para la realización de derechos fundamentales, sobre todo en cuanto a limitaciones a los derechos fundamentales como la privación de la libertad en la administración de justicia penal o en el ingreso en una institución. Estas importantes áreas también incluyen asuntos culturales como la disposición del lenguaje, el delineamiento de circunstancias que conciernen a la familia y educación, el establecimiento de orden en la libertad de opinión, de prensa y de asociación, y de la libertad de religión y de conciencia." 60 Esto, sostuvo el Tribunal, abarca el principio que el castigo debe estar ligado a la culpa personal $^{61} \mathrm{y}$, en el contexto de la protección de datos, el principio de que "las acciones de los ciudadanos tal vez no estén totalmente cubiertas y grabadas." 62

El Tribunal Constitucional Federal Alemán por tanto, va más allá que los tribunales constitucionales de otros Estados Miembros, deduciendo desde los principios abstractos de la organización del Estado, límites más bien específicos para la conducta de la UE. ${ }^{63}$ La jurisprudencia del Tribunal Constitucional Federal Alemán llama la atención de forma particular porque visualiza estos límites especificos como derivaciones de la "cláusula de eternidad" de la Constitución alemana. Las modificaciones correspondientes, en otras palabras, requieren mutar la estructura de la Constitución alemana, lo que, de facto, acarrearía una revolución legal. ${ }^{64}$ Es objetable que por su jurisprudencia, el Tribunal Constitucional Federal Alemán ponga el poder legislativo en una camisa, paralizar a lo demás al proceso de integración europea.

No obstante, a pesar de algunas diferencias en el énfasis y en el grado de diferenciación en la materia, se ve que los tribunales constitucionales de los 
Estados Miembros basan su comprensión de la identidad nacional (constitucional) en percepciones similares. Sobre todo, debe advertirse que el Tratado de Lisboa, al otorgar al concepto de identidad nacional una posición prominente, parece haber tenido éxito en dar un sólo marco conceptual a los variados discursos en los Estados Miembros en cuanto a la relación entre el derecho europeo y el derecho constitucional nacional. Este logro no es menor considerando que la existencia de un discurso europeo común en el contexto de un asunto tan delicado como la relación entre el derecho constitucional y el ordenamiento de la UE, es de vital importancia. A lo demás, el respeto por la identidad nacional en el Artículo 4, párrafo 2 TUE es una norma en que resueno el concepto que el derecho europeo y el derecho constitucional nacional no están separados como differentes ordenamientos legales, pero están vinculados de una manera inherente como parte de una constitución compuesta.

\section{CONSECUENCIAS LEGALES E IMPLEMENTACIÓN PROCEDIMENTAL DEL RESPETO POR LA IDENTIDAD NACIONAL}

\section{La obligación de respeto}

El Artículo 4, párrafo 2 TUE establece una obligación de respeto que se aplica a las instituciones de la UE. Por lo tanto, no establece una protección absoluta, sino requiere un balance proporcional entre la aplicación uniforme del derecho europeo, que es un principio constitucional fundamental de la Unión, ${ }^{65}$ por un lado, y la identidad nacional, por el otro. ${ }^{66}$ Del mismo modo, el Artículo 4, párrafo 2 TUE, no otorga prioridad a valores particulares de los Estados Miembros sobre el derecho de la UE; solo previene que la UE interfiera de forma desproporcionada con valores constitucionales nacionales. ${ }^{67}$

Al hacer operativo el ámbito del deber de respeto, se puede contar con la jurisprudencia establecida del TJUE sobre choques entre libertades fundamentales y derechos constitucionales fundamentales. En ella, el TJUE en principio concuerda con la primacía del derecho europeo sobre el derecho constitucional nacional, ${ }^{68}$ pero emplea el análisis de proporcionalidad para ponderar las obligaciones de los Estados Miembros bajo el orden de la UE y la protección de los derechos fundamentales bajo el derecho constitucional doméstico. ${ }^{69}$

En lo que se refiere a las consecuencias legales que la cláusula de identidad pueda tener, se pueden distinguir dos constelaciones. Primero, una interferencia desproporcionada de un acto de las instituciones europeas con un valor constitucional protegido bajo el Artículo 4, párrafo 2 TUE puede ser motivo para que el TJUE declare un acto ilegal. Segundo, el Artículo 4, párrafo 2 TUE también puede ser invocado como justificación por un Estado Miembro para no cumplir con una obligación impuesta por el derecho europeo, sin que eso convierta en ilegal a la medida de la UE. En este aspecto, el Artículo 4, párrafo 2 TUE puede ser usado para justificar el no cumplimiento por un Estado Miembro con normas de la UE, en particular al momento de implementar directivas de la Unión. En todo caso, esto sólo puede ser invocado en circunstancias excepcionales. Una justificación para un incumplimiento bajo el 
amparo del Artículo 4, párrafo 2 TUE requiere además, que la medida nacional en cuestión sea proporcionada y aplicada de conformidad con la Constitución del Estado Miembro. ${ }^{70}$

\section{Implementación procedimental de la jurisdicción constitucional compuesta}

Conflictos entre el derecho de la UE y el derecho constitucional nacional no tienen sólo un lado sustancial sino que también un lado procedimental. La pregunta que entonces surge es: ¿Quién decide acerca de las consecuencias legales que ocurren y quién determina el balance entre el derecho europeo y la identidad nacional? ¿Será el TJUE o los tribunales constitucionales nacionales? Esta pregunta es particularmente conflictiva dada la afirmación de numerosos tribunales nacionales en el sentido de que ellas determinarían los actos de la UE fueran de conformidad a ciertos principios constitucionales.

Así, el Tribunal Constitucional Federal Alemán en particular se visualiza teniendo la potestad de determinar el ámbito de la identidad nacional de manera soberana cuando afirma que el control de identidad es una vía específica de control de constitucionalidad de actos de la UE. ${ }^{71}$ Como una razón para justificar este poder, el Tribunal señala que de otro modo, los límites del Artículo 4 párrafo 2 TUE no podrían ser efectivamente controlados. ${ }^{72}$ La consecuencia legal de una vulneración del Artículo 4, párrafo 2 TUE, desde su perspectiva, es la inaplicabilidad de un acto de la UE en Alemania. ${ }^{73} \mathrm{De}$ manera similar, otros los tribunales indican, aunque de forma más cautelosa en sus formulaciones, que tienen "la última palabra" en el contenido de la identidad nacional. $^{74}$

Dichas posiciones son difíciles de sostener. En su lugar, la tensión entre el TJUE y los tribunales constitucionales y supremos de los Estados Miembros debería regularse por el principio de cooperación leal que se consagra en el Artículo 4, párrafo 3 TUE. Esta disposición puede ser vista como el fundamento legal para la cooperación entre todos los tribunales constitucionales europeos. Desde esa perspectiva, se puede señalar que el TJUE y las más altos tribunales y cortes de los Estados Miembros son partes complementarias de una jurisdicción constitucional compuesta. ${ }^{75}$ También, el principio de coopercaión leal requiere estrategias mutuas de prevención de conflictos entre el TJUE y los tribunales constitucionales dómesticos. ${ }^{76}$

El principio de cooperación leal se opone a una posición autocrática de los tribunales nacionales que puede ser una seria amenaza a la comunidad legal europea. Desde al perspectiva procesal, es entonces necesario que un control de identidad por los tribunales constitucionales nacionales sea conducido solo despues de hacer uso de una referencia preliminar del Art. 267 TFUE. Este procedimiento es aplicable tanto a los tribunales constitucionales como a cualquier otra corte de los Estados Miembros. ${ }^{77}$ Un tribunal constitucional o suprema, si desea basarse en el Artículo 4, párrafo 2 TUE para excusarse de cumplir con el ordenamiento de la UE, debe entonces expresar sus reparos en torno al respeto de la identidad nacional en una referencia preliminar al TJUE. 
Al mismo tiempo, se puede notar que el TJUE, como órgano de la UE, está sujeta a la obligación bajo el Artículo 4, párrafo 2 TUE de respetar la identidad nacional de los Estados Miembros. En su decisión sobre la interpretación del Artículo 4, párrafo 2 TUE, el TJUE deberá tomar en consideración la comprensión específica del derecho constitucional, de la forma en que lo interpreta el tribunal constitucional nacional, en cuanto al significado de la identidad nacional para el estado en cuestión. ${ }^{78}$ Además, el principio de cooperación leal requiere que el TJUE otorgue un margen de apreciación para que los tribunales constitucionales nacionales acomoden sus respectivos entendimientos acerca de la identidad nacional bajo el Artículo 4, párrafo 2 TUE. ${ }^{79}$ Como no hay un procedimiento de transferencia desde el TJUE a un tribunal constitucional nacional, el TJUE debe asegurare que el gobierno del Estado Miembro someta el tema a la perspectiva del tribunal constitucional de ese Estado. ${ }^{80}$

Es una característica inherente al constitucionalismo pluralista europeo que una decisión del TJUE sobre el respeto a la identidad nacional y sus consecuencias en casos específicos no es definitiva, ya que la Unión carece de una estructura jerárquica. El ordenamiento europeo no puede prevenir que los tribunales constitucionales de los Estados Miembros interpreten el contenido de la identidad nacional de forma diferente desde la perspectiva del derecho constitucional. Con todo, esto parece ser un precio aceptable para una estructura constitucional que no es jerárquica. ${ }^{81}$

Dicho orden no jerárquico, sin embargo, puede ser sustentable sólo si los tribuanales nacionales toman en serio el principio de cooperación leal. ${ }^{82}$ Esto requiere que ellos interpreten cualquier reserva constitucional de forma estricta y que tengan presente que tienen una responsabilidad no sólo para la integridad de su ordenamiento constitucional nacional, sino también para el orden europeo y la integración europea en general. Pues, las decisiónes de los tribunales constitucionales nacionales inevitablemente affectan la situación de los otros Estados Miembros y de sus tribunales constitucionales. ${ }^{83}$

\section{CONCLUSIÓN}

La concepción pluralista de la relación entre el derecho de la UE y el derecho constitucional nacional adquiere relevancia con la introducción de la cláusula de identidad del Artículo 4, párrafo 2 TUE. La idea del enfoque de "conflictos de derecho constitucional" que influenció la antigua jurisprudencia de los tribunales constitucionales domésticos en relación a la colisión entre el derecho constitucional doméstico y el derecho europeo, desaparece. En su lugar, el Artículo 4, párrafo 2 TUE constitucionaliza la relación entre el ordenamiento de la UE y el derecho constitucional doméstico al convertir las reservas constitucionales en un asunto, primero y ante todo, de interpretación del Tratado de la UE. Esto supera no solamente la "ceguera" del ordenamiento europea en relación a las reservas constitucionales de los tribunales constitucionales nacionales, pero también la primacía absoluta y incondicional del derecho de la Unión. Por lo contrario, los tribunales constitucionales 
nacionales y el TJEU tienen que trabajar juntos como parte de una jurisdicción constitucional compuesta que reconcilia el derecho europeo y las consideraciones de los derechos constitucionales nacionales. En este sentido, el respeto por la identidad nacional en el Artículo 4, párrafo 2 TUE y el principio de cooperación leal pueden ser dos elementos para ayudar a la superación de las posiciones incompatibles del TJUE $z$ de los tribunales constitucionales nacionales en cuanto a la cuestión de primacía y a reconciliar la tormentosa relación entre el derecho constitucional nacional y el derecho europeo.

\title{
NOTES
}

\begin{abstract}
* Senior Research Fellow, Max Planck Institute for Comparative Public Law and International Law, Heidelberg; Rechtsanwalt (admitido al bar en Alemania); Attorney-at-Law (New York); LL.M. Derecho Económico Europeo e Internacional (Universität Augsburg, 2002); LL.M. International Legal Studies (New York University, 2006); Dr. iur. (Johann Wolfgang Goethe-Universität Frankfurt am Main, 2008). El autor quiere agradecer a Stefano Perreta del Heidelberg Center para América Latina, Santiago de Chile, para la traducción de este articulo de Ingles a Español.
\end{abstract}

TJUE, Costa/ENEL (6/64), Rec. 1964, 1251, 1269 et seq.; más recien TJUE, Winner Wetten (C-409/06), 8 Septiembre 2010, Rec. 2010, I-0000 párras. 53 et seq.

2. TJUE, Internationale Handelsgesellschaft (11/70), Rec. 1970, 1125 pár. 3; Simmenthal (106/77), Rec. 1978, 629 párras. 21 et seq.; Comisión/Bélgica (149/79), Rec. 1980, 3881 pár. 19; Brasserie du Pêcheur/ Factortame II (asuntos acumulados C-46/93 y C-48/93), Rec. 1996, I1029 pár. 33; Comisión/Luxemburgo (C-473/93), Rec. 1996, I-3207 párras. 37 et seq.; IN.CO.GE.'90 et al. (asuntos acumulados C-10/97 - C-22/97) Rec. 1998, I-6307 párras. 11, 20 et seq.; Michaniki (C-213/07), Rec. 2008, I-9999 párras. 62 et seq.

3. TJUE, Tanja Kreil (C-285/98), Rec. 2000, I-95 párras. 25 et seq.

4. Sentenecia del Tribunal Constitucional Federal Alemán (STCF), tomo 37, pp. 271, 277 et seq. (1974) (Solange I).

5. STCF, tomo 73, pp. 339, 378 et seq. (1986) (Solange II).

6. Este control ahora encierra tres variantes: 1) control de actos de la UE para armonizar con derechos fundamentales, control que no se ejerce actualmente; véase STCF, tomo 37, pp. 271, 277 et seq. (1974) (Solange ); tomo 73, pp. 339, 378 et seq. (1986) (Solange II); tomo 102, pp. 147, 161 et seq. (2000) (Bananenmarktordnung); 2) control de actos de la UE para adecuarse a reglas de competencia (control-ultra vires); véase STCF, tomo 89, pp. 155, 188 (1993) (Maastricht); este control se ejerce de una manera muy limitada; véase STCF, Decisión de 6/7/2010, párras. 54 et seq., http://www.bverfg.de (Honeywell); y 3) control de conformidad de actos de la UE con la identidad constitucional de Alemania; véase STCF tomo 123, pp. 267, 353 et seq. (2009) (Lissabon).

7. Para la debate sobre la primacía de derecho de la UE y las relaciónes entre la TJUE y las differentes tribunales constitucionales nacionales véase $C$. Grabenwarter, Staatliches Unionsverfassungsrecht, en: A. von Bogdandy/J. Bast (eds.), Europäisches Verfassungsrecht, $2^{a}$ ed. 2009, p. 121; P. M. Huber, Offene Staatlichkeit: Vergleich, en: A. von Bogdandy/P. Cruz Villalón/P. M. Huber (eds.), Handbuch lus Publicum Europaeum, tomo II, 2008 (en lo que sigue IPE II), § 26 párras. 34 et seq.; A. Albi, Supremacy of EC Law in the Member States, Eur. Const. L. Rev. 3 (2007), p. 25; F. C. Mayer, Kompetenzüberschreitung und Letztbegründung, 2000, pp. 76 et seq.; F. C. Mayer, Verfassungsgerichtsbarkeit, en: A. von Bogdandy/J. Bast (supra nota Erro! Indicador não definido.), p. 559; A.-M. Slaughter/A. Sweet Stone/J. H. H. Weiler (eds.), The European Court and National Courts - Doctrine and Jurisprudence, 1998; C. Grewe/H. Ruiz Fabri, Droits constitutionnels européens, 1995, pp. 118 et seq.; M. Cartabia/B. de Witte/P. Pérez Tremps (eds.), Constitución europea y constituciones nacionales, 2005; G. Bosco, La primauté du droit communautaire dans les ordres juridiques des Etats membres de I'Union européenne, en: O. Due/M. Lutter/J. Schwarze (eds.), Festschrift für Ulrich Everling, 1995, p. 149; K. Alter, Establishing the Supremacy of European Law. The Making of an International Rule of Law in Europe, 2001; A. Celotto/T. Groppi, Diritto UE e diritto nazionale: 
Primauté vs controlimiti, Riv. ital. dir. pubb. Com. 14 (2004), p. 1309; M. Claes, The National Courts' Mandate in the European Constitution, 2006, pp. 387 et seq. Véase también la jurisprudencia de los tribunales constitucionales dómesticos supra notes Erro! Indicador não definido.-Erro! Indicador não definido..

8. En la década de los 90 , la noción de Verbund era inicialmente parte de los dos enfoques competidores del (principalmente intergubernamental) Staatenverbund (conjunto de Estados) desarrollado por Paul Kirchhof y la aproximación (más federal) del Verfassungsverbund (constitucionalismo compuesto) de Ingolf Pernice. Véase $P$. Kirchhof, Der europäische Staatenverbund, en: A. von Bogdandy/J. Bast (supra nota Erro! Indicador não definido.), p. 1009 y I. Pernice, Multilevel Constitutionalism in the European Union, Eur. L. Rev. 5 (2002), p. 511. Hoy, el término está libre de estas dos visiones contrapuestas, recibiendo un amplio reconocimiento entre los académicos de derecho constitucional. Véase $C$. Schönberger, Die Europäische Union als Bund, Archiv des öffentlichen Rechts (AöR) 129 (2004), p. 81; véase también los contribuciónes en $C$. Calliess (ed.), Verfassungswandel im europäischen Staatenund Verfassungsverbund, 2007.

9. A. Voßkuhle, Der europäische Verfassungsverbund, Neue Zeitschrift für Verwaltungsrecht (NVwZ) 2010, p. 1.

10. E. Schmidt-Aßmann, Einleitung: Der Europäische Verwaltungsverbund und die Rolle des Europäischen Verwaltungsrechts, en: E. Schmidt-Aßmann/B. Schöndorf-Haubold, Der Europäische Verwaltungsverbund, 2005, pp. 1, 6 et seq.; Voßkuhle (supra nota Erro! Indicador não definido.), p. 3.

11. No obstante la TJUE utilizó el concepto de la coóperación leal para requerir a los organos de la UE de respetar consideraciónes fundamentales en las constituciónes de los Estados Miembros. Véase T. Giegerich, Europäische Verfassung und deutsche Verfassung im transnationalen Konstitutionalisierungsprozeß, 2003, pp. 792 et seq.; A. Wille, Die Pflicht der Organe der Europäischen Gemeinschaft zur loyalen Zusammenarbeit mit den Mitgliedstaaten, 2003, pp. 150 et seq.; W. Kahl, en: Calliess/Ruffert, EUV/EGV, 3르 ed. 2007, Art. 10 EGV, párras. 70 et seq. (con más referencias).

12. M. Kumm/V. Ferreres Comella, The Primacy Clause of the Constitutional Treaty and the Future of Constitutional Conflict in the European Union, Int'I J. Const. L. 3 (2005), pp. 473, 491-492; M. Kumm, The Jurisprudence of Constitutional Conflict: Constitutional Supremacy in Europe before and after the Constitutional Treaty, Eur. L. J. 11 (2005), pp. 262, 302-304.

13. TJUE, Comisión/Luxemburgo (C-473/93), Rec. 1996, I-3207 pár. 35.

14. TJUE, Comisión/Luxemburgo (C-473/93), Rec. 1996, I-3207 párras. 35 et seq.

15. TJUE, Schmidberger (C-112/00), Rec. 2003, I-5659 párras. 71 et seq. Véase también $L$. González Vaqué, El difícil equilibrio entre la libre circulación de mercancías y los derechos fundamentales en materia de libertad de expresión y de reunión: la sentencia "Schmidberger", Gaceta Jurídica de la U.E. y de la Competencia 227 (2003), p. 61.

16. TJUE, Omega (C-36/02), Rec. 2004, I-9609 párras. 33 et seq.

17. TJUE, Viking (C-438/05), Rec. 2007, I-10779 párras. 45 et seq., 75 et seq.; Laval un Partneri (C-341/05), Rec. 2007, I-11767 párras. 87 et seq. Véase también A. Baylos Grau, El espacio supranacional de ejercicio des derecho de huelga y la restriccion de sus capacidades de acción, Rev. Der. Soc. 41 (2008), p. 123.

18. TJUE, Familiapress (C-368/95), Rec. 1997, I-3689 pár. 18; United Pan-Europe Communications Belgium et al. (C-250/06), Rec. 2007, I-11135 párras. 41 et seq.

19. TJUE, Dynamic Medien (C-244/06), Rec. 2008, I-505 párras. 36 et seq.

20. R. Wahl, Europäisierung: Die miteinander verbundene Entwicklung von Rechtsordnungen als ganzen, en: H. H. Trute/T. Groß/H. C. Röhl/C. Möllers (eds.), Allgemeines Verwaltungsrecht - zur Tragfähigkeit eines Konzepts, 2008, p. 869.

21. Véase A. Verdross/B. Simma, Universelles Völkerrecht, $3^{3}$ ed. 1984, pp. 25 et seq.; M. N. Shaw, International Law, 6 ed. $^{\mathrm{a}}$ 2008, pp. 21 et seq.; J. Combacau/S. Sur, Droit international public, $8^{\underline{a}}$ ed. 2008, pp. 236 et seq.

22. Es a notar que esta regla ya ha formado parte, como la cláusula de identidad, del Tratado Constitucional. Se remonta a una propuesta referida como la "cláusula Christophersen" formulada durante la deliberación en la Convención Constitucional. Véase CONV 375/02, pp. 10 et seq.; CONV 251/02, p. 3.

23. CONV 400/02, p. 13. 
24. La obligación de la Union de respetar la diversidad cultural y de lenguaje se encuentra en el Artículo 3, párrafo 3 TUE.

25. M. Hilf, Europäische Union und nationale Identität der Mitgliedstaaten, en: A. Randelzhofer/R. Scholz/D. Wilke (eds.), Gedächtnisschrift für Eberhard Grabitz, 1995, p. 163; cfr. también M. Morlok, Selbstverständnis als Rechtskriterium, 1993, pp. 34 et seq.

26. En el mismo sentido AG Maduro, Michaniki (C-213/07), Rec. 2008, I-9999 pár. 33; A. Epiney, Zur Tragweite des Art. 10 EGV im Bereich der Außenbeziehungen, en: J. Bröhmer/R. Bieber/C. Calliess/C. Langenfeld/S. Weber/J. Wolf (eds.), Internationale Gemeinschaft und Menschenrechte, Festschrift für Georg Ress, 2005, pp. 441, 446; E. Di Salvatore, L'identità costituzinale dell'Unione europea e degli Stati membri, 2008, p. 35 et seq.

27. TJUE, Omega (C-36/02), Rec. 2004, I-9609 párras. 37 et seq. (con más referencias); Dynamic Medien (C-244/06), Rec. 2008, I-505 párras. 44 et seq.; véase también AG Maduro, Michaniki (C-213/07), Rec. 2008, I-9999 párras. 32, 34.

28. Huber (supra nota Erro! Indicador não definido.) párras. 38; $A$. Weber, Europäische Verfassungsvergleichung, 2010, pp. 430 et seq.

29. P. Cruz Villalón, in: A. von Bogdandy/P. Cruz Villalón/P. M. Huber (eds.), Handbuch lus Publicum Europaeum, tomo I, 2007, § 13 párras. 141; en detalle Weber (supra nota Erro! Indicador não definido.), pp. 45 et seq., 398 et seq., 429 et seq.

30. A. Weber, Die Europäische Union unter Richtervorbehalt?, Juristenzeitung (JZ) 2010, p. 157; W. Sadurski, 'Solange, chapter 3': Constitutional Courts in Central EuropeDemocracy-European Union, Eur. L. J. 14 (2008), p. 1; Huber (supra nota Erro! Indicador não definido.), párras. 34 et seq.

31. Véase Tribunal Constitucional Polaco, Caso K 18/04 de 11/5/2005, Europarecht (EuR) 2006, pp. 236, 238 et seq.; Tribunal Constitucional Lituano, asuntos acumulados 17/02, 24/02, 06/03, 22/04 de 14/3/2006, apdo. III, pár. 9.4, http://www.Irkt.It/dokumentai/2006/r060314.htm (10/5/2010). La situación en Grecia es difusa. Véase J. lliopoulos-Strangas, Offene Staatlichkeit: Griechenland, IPE II, § 16 párras. 37 et seq.

32. Corte Constitucionale Italiana, Caso 183/1973 de 18/12/1973 (Frontini), Europäische Grundrechtezeitschrift (EuGRZ) 1975, pp. 311, 315; Caso 170/84 de 8/6/1984 (Granital), en: A. Oppenheimer, The Relationship between European Community Law and National Law, tomo I, 1994, pp. 643, 651; Caso 232/1989 de 13 resp. 21/4/1989 (Fragd), en: Oppenheimer (nota Erro! Indicador não definido.), pp. 653, 657.

33. $\quad$ STCF tomo 37, pp. 271, 277 et seq. (1974) (Solange 1); tomo 73, pp. 339, 378 et seq. (1986) (Solange II); 89, 155, 188 (1993) (Maastricht); tomo 123, pp. 267, 353 et seq. (2009) (Lissabon).

34. Crotty v. An Taoiseach, [1987] IR 173; Society for the Protection of Unborn Children (Ireland) Ltd. v. Grogan, [1989] IR 753; Attorney General v. X, [1992] 1 IR 1.

35. Corte Suprema Danés, Caso I 361/1997 de 6/4/1998, EuGRZ 1999, pp. 49, 52.

36. Al respecto de la evolución de la jurisprudencia del Tribunal Constitucional Español véase A. C. Becker, Vorrang versus Vorherrschaft, Europarecht (EuR) 2005, p. 353; A. López Castillo, Offene Staatlichkeit: Spanien, en: von IPE II, § 24 párras. 67 et seq.

37. Véase, por ejemplo, Consejo Constitucional Francés, 2006-540 DC de 27/7/2006, Recueil des décisions 2006, pp. 88, 92. Véase también S. Pinon, L'effectivité de la primauté du droit communautaire sur la Constitution, Rev. Trim. Dr. Eur. 44 (2008), p. 263; C. Richards, The Supremacy of Community Law before the French Constitutional Court, Eur. L. Rev. 31 (2006), p. 499.

38. Véase también Sadurski (supra nota Erro! Indicador não definido.), pp. 9 et seq.; $P$. Sonnevend, Offene Staatlichkeit: Ungarn, IPE II, § 25 párras. 33 et seq.

39. Tribunal Constitucional Czeco, Caso PI. ÚS 50/04 de 8/3/2006; Caso PI. ÚS 66/04 de 3/5/2006, pár. 53; Caso PI. ÚS 19/08 de 22/11/2008, pár. 120, http://www.concourt.cz; Caso PI. ÚS 29/09 de 3/11/2009, pár. 150, EuGRZ 2010, pp. 209, 229

40. Cfr. Tribunal Constitucional Polaco, Caso K 18/04 de 11/5/2005, EuR 2006, pp. 236, 243 et seq.; Caso Kp 3/08 de 18/2/2009, http://www.trybunal.gov.pl. El Tribunal Constitucional Lituano por su parte ya presentó una referencia preliminar al TJUE; véase TJUE, Sabatauskas (C-239/07), Rec. 2008, I-7523.

41. STCF tomo 113, pp. 273, 298 et seq. (2005) (Europäischer Haftbefehl; tomo 123, pp. 267, 343 (2009) (Lissabon); cfr. también Tribunal Constitucional Polaco, Caso K 18/04 de 
11/5/2005, EuR 2006, pp. 236, 238 et seq.; Corte Suprema Danés, Caso I 361/1997 de 6/4/1998, EuGRZ 1999, pp. 49, 52; Tribunal Constitucional Español, Caso 1/2004 de 13/12/2004, EuR 2005, pp. 339, 343; Tribunal Constitucional Czeco, Caso PI. ÚS 50/04 de 8/3/2006; Caso PI. ÚS 66/04 de 3/5/2006, pár. 53; Caso PI. ÚS 19/08 de 22/11/2008, pár. 97; Tribunal Constitucional Letón, Caso 2008-35-01 de 7/4/2009, pár. 17, http://www.satv.tiesa.gov.lv.

STCF tomo 92, pp. 203, 237 (1995) (EG-Fernsehrichtlinie).

43. STCF tomo 113, pp. 273, 299 (2005) (Europäischer Haftbefeh); cfr. auch STCF tomo 123, pp. 267, 341 (2009) (Lissabon); Tribunal Constitucional Czeco, Caso PI. ÚS 50/04 de 8/3/2006; Tribunal Constitucional Léton, Caso 2008-35-01 de 7/4/2009, pár. 17.

44. STCF tomo 89, pp. 155, 182 et seq. (1993) (Maastricht); tomo 123, pp. 267, 343 (2009) (Lissabon); Tribunal Constitucional Czeco, Caso PI. ÚS 50/04 de 8/3/2006; Tribunal Constitucional Léton, Caso 2008-35-01 de 7/4/2009, pár. 17; véase también Tribunal Constitucional Polaco, Caso. K 18/04 de 11/5/2005, EuR 2006, pp. 236, 238 et seq.

45. $\quad$ STCF tomo 37, pp. 271, 280 (1974) (Solange ); tomo 58, pp. 1, 40 (1981) (Eurocontrol); tomo 73, pp. 339, 376 (1986) (Solange II); Tribunal Constitucional Polaco, Caso K 18/04 de 11/5/2005, EuR 2006, pp. 236, 239 et seq.; Corte Suprema Danés, Caso I 361/1997 de 6/4/1998, EuGRZ 1999, pp. 49, 50; Tribunal Constitucional Español, Caso. 1/2004 de 13/12/2004, EuR 2005, pp. 339, 343; Corte Constitucionale Italiana, Caso 183/1973 de 18/12/1973 (Frontini), EuGRZ 1975, pp. 311, 315; Caso 170/84 de 8/6/1984 (Granital), en: Oppenheimer (supra nota Erro! Indicador não definido.), p. 651; Caso 232/1989 de 13 resp. 21/4/1989 (Fragd), en: Oppenheimer (supra nota Erro! Indicador não definido.), p. 657; Tribunal Constitucional Czeco, Caso PI ÚS 19/08 de 22/11/2008, párras. 110, 196.

46. Véase las decisiones mencionadas supra nota Erro! Indicador não definido.. De manera similar también Consejo Constitucional Francés, Caso 2006-540 DC de 27/7/2006, Recueil des décisions 2006, pp. 88, 92; Tribunal Constitucional Czeco, Caso PI. ÚS 50/04 de 8/3/2006; Caso PI. ÚS 66/04 de 3/5/2006, pár. 53.

47. Tribunal Constitucional Czeco, Caso PI ÚS 19/08 de 22/11/2008, pár. 109; Caso PI. ÚS 29/09 de 3/11/2009, párras. 110 et seq., EuGRZ 2010, pp. 209, 222 et seq.; Corte Suprema Danés, Caso I 361/1997 de 6/4/1998, EuGRZ 1999, pp. 49, 52.

48. Tribunal Constitucional Czeco, Caso PI Ús 19/08 de 22/11/2008, pár. 208.

49. STCF tomo 58, pp. 1, 37 (1981) (Eurocontrol); tomo 89, pp. 155, 187 et seq. (1993) (Maastricht); Corte Suprema Danés, Caso I 361/1997 de 6/4/1998, EuGRZ 1999, 49, pp. 50, 52; Tribunal Constitucional Léton, Caso. 2008-35-01 de 7/4/2009, pár. 18.2; Tribunal Constitucional Polaco, Caso K 18/04 de 11/5/2005, EuR 2006, pp. 236, 238; Tribunal Constitucional Czeco, Caso PI ÚS 19/08 de 22/11/2008, pár. 135, 186; Caso PI. ÚS 29/09 de 3/11/2009, pár. 133, EuGRZ 2010, pp. 209, 226.

50. $\quad$ STCF tomo 58, pp. 1, 40 et seq. (1981) (Eurocontrol); tomo 73, pp. 339, 372, 376, 381 (1986) (Solange II); tomo 113, pp. 273, 298, 309 et seq. (2005) (Europäischer Haftbefeh); tomo 123, pp. 267, 416 (2009) (Lissabon); Corte Constitucionale Italiana, Caso 232/1989 de 13 resp. 21/4/1989 (Fragd), en: Oppenheimer (nota Erro! Indicador não definido.), p. 653, 657.

51. STCF tomo 73, pp. 339, 380 (1986) (Solange II); 113, 273, 299 (2005) (Europäischer Haftbefeh).

52. $\quad$ STCF tomo 73, pp. 339, 381 (1986) (Solange II).

53. $\quad$ STCF tomo 73, pp. 339, 381 (1986) (Solange II).

54. Véase sobre todo STCF tomo 37, pp. 271, 279 et seq. (1974) (Solange 1); tomo 58, pp. 1, 40 (1981) (Eurocontrol); tomo 73, pp. 339, 376 (1986) (Solange II); tomo 89, pp. 155, 174 et seq. (1993) (Maastricht).

55. STCF tomo 89, pp. 155, 182, 213 (1993) (Maastricht); tomo 123, pp. 267, 357 et seq. (2009) (Lissabon).

56. STCF tomo 123, pp. 267, 343, 353 et seq. (2009) (Lissabon).

57. STCF tomo 123, pp. 267, 343 (2009) (Lissabon).

58. STCF tomo 123, pp. 267, 357 et seq. (2009) (Lissabon).

59. STCF tomo 123, pp. 267, 358 (2009) (Lissabon).

60. STCF tomo 123, pp. 267, 359 (2009) (Lissabon).

61. STCF tomo 123, pp. 267, 413 (2009) (Lissabon).

62. STCF, Decisión de 2/3/2010, Neue Juristische Wochenschrift (NJW) 2010, pp. 833, 839. 
63. En consecuencia la sentecia del Tribunal Constitucional Federal Alemán fue criticada de manera intensiva. Véase, pr ejemplo, D. Halberstam/C. Möllers, The German Constitutional Court Says "Ja zu Deutschland?", German L. J. 10 (2009), p. 1241; J. P. Terhechte, Souveränität, Dynamik und Integration - making up the rules as we go along?, Europäische Zeitschrift für Wirtschaftsrecht (EuZW) 2009, p. 724; M. Kottmann/C. Wohlfahrt, Der gespaltene Wächter? - Demokratie, Verfassungsidentität und Integrationsverantwortung im Lissabon-Urteil, Zeitschrift für ausländisches öffentliches Recht und Völkerrecht (ZaöRV) 69 (2009), p. 443; U. Everling, Europas Zukunft unter der Kontrolle der nationalen Tribunal Constitucionale, EuR 2010, p. 91; C. Schönberger, Lisbon in Karlsruhe: Maastricht's Epigones at Sea, German L. J. 19 (2009), p. 1201.

64. P. M. Huber, en: Sachs, GG Kommentar, $5^{\text {a }}$ ed. 2008, Art. 146 GG, párras. 13 y 16 et seq.; H. Dreier, en: H. Dreier, GG Kommentar, tomo III, 2ª ed. 2008, Art. 146 GG, párras. 33 et seq.

65. A. von Bogdandy, Grundprinzipien, en: von Bogdandy/Bast (supra nota Erro! Indicador não definido.), pp. 13, 36 et seq.

66. Hilf (supra nota Erro! Indicador não definido.), p. 164; W. Kahl, en: Calliess/Ruffert, EUV/EGV, 3를 ed. 2007, Art. 10 EGV, pár. 72; R. Streinz, en: Streinz, EUV/EGV, 2003, Art. 10 EGV, párras. 49 et seq.; C. Stumpf, en: Schwarze, EU-Kommentar, $2^{\mathrm{a}}$ ed.. 2008, Art. 6 EUV, pár. 40.

67. Véase Declaración No. 20 sobre Artículo 16 TFUE, JO C 115/355. Este también es el significado usual del término "respeto" de la forma en que es empleado en la Carta de Derechos Fundamentales de la UE. Véase Artículos 7, 11(2), 13, 22, 25, 26, 34(1), 34(3), 36, 48(2) de la Charta en connection con Artículo 52, párrafo 1 de la Charta.

68. Véase la jurisprudence del TJUE supra nota Erro! Indicador não definido..

69. TJUE, Comisión/Luxemburgo (4 C-73/93), Rec. 1996, I-3207 párras. 35 et seq.; Michaniki (C-213/07), Rec. 2008, I-9999 párras. 61 et seq. Cfr. también la jurisprudencia y la doctrina mencionada supra notas Erro! Indicador não definido.-Erro! Indicador não definido..

70. Así, el TJUE ha sostenido que una disposición en la Constitución griega que excluía a las empresas constructoras que estaban vinculadas a empresas de medios de comunicación de participar en compras públicas, era, en principio, posible, pero desproporcionada dada las circunstancias del caso. Esto muestra entonces, cómo el TJUE emplea una aproximación conciliadora para equilibrar el interés de la UE de implementar su ordenamiento y el de los Estados Miembros para mantener la eficacia de su derecho constitucional nacional. TJUE, Michaniki (C-213/07), Rec. 2008, I-9999 párras. 61 et seq.

71. STCF tomo 123, pp. 267, 354 (2009) (Lissabon).

72. STCF tomo 123, pp. 267, 354 (2009) (Lissabon).

73. STCF tomo 123, pp. 267, 354 (2009) (Lissabon).

74. Véase supra notas Erro! Indicador não definido.-Erro! Indicador não definido. y texto acampañador.

75. Voßkuhle (supra nota Erro! Indicador não definido.).

76. T. von Danwitz, Europäisches Verwaltungsrecht, 2008, p. 153.

77. En realidad, ya algunos tribunales constitucionales y cortes supremas de varios Estados Miembros han hecho referencias preliminares al TJUE. Véase AG Kokott, Presidente del Consiglio (C-169/08), Rec. 2009, I-10821 pár. 21.

78. Cfr. Tribunal Constitucional Polaco, Caso K 18/04 de 11/5/2005, EuR 2006, pp. 236, 243.

79. En este sentido en el contexto differente de interpretar los conceptos de orden público y seguridad TJUE, Rutili (36/75), Rec. 1975, 1219 párras. 26 et seq.; Bouchereau (30/77), Rec. 1977, 1999 párras. 33/35; Église de scientologie (C-54/99), Rec. 2000, I-1335 pár. 17; Gheorghe Jipa (C-33/07), Rec. 2008, I-5157 pár. 23. De manera similar en el context de interpreter el concepto de moral pública TJUE, Henn u. Derby (34/79), Rec. 1979, 3795 pár. 15. 80. El TJUE tiene la competencia para esto. Cfr. Art. 24 der Satzung des Gerichtshofes.

81. Fundamental sobre la jerarquía como elemento de ordenes constitucionales en la UE y los Estados Unidos D. Halberstam, Constitutional Hierarchy: The Centrality of Conflict in the European Union and the United States, in: J. L. Dunoff/J. Trachtman (eds.), Ruling the World? Constitutionalism, International Law, and Global Governance, 2009, pp. 326 et seq. 
82. Huber (supra nota Erro! Indicador não definido.), párras. 80 et seq. Véase también $R$. Wahl, Die Schwebelage im Verhältnis von Europäischer Union und Mitgliedstaaten, Der Staat 48 (2010), pp. 587, 603 et seq.

\section{REFERENCIAS}

\section{Jurisprudencia}

a. $\quad$ Tribunal de Justicia de la Union Europea (TJUE)

TJUE, Costa/ENEL (6/64), Rec. 1964, 1251

TJUE, Internationale Handelsgesellschaft (11/70), Rec. 1970, 1125

TJUE, Rutili (36/75), Rec. 1975, 1219

TJUE, Bouchereau (30/77), Rec. 1977, 1999

TJUE, Simmenthal (106/77), Rec. 1978, 629

TJUE, Henn u. Derby (34/79), Rec. 1979, 3795

TJUE, Comisión/Bélgica (149/79), Rec. 1980, 3881

TJUE, Brasserie du Pêcheur/Factortame II (asuntos acumulados C-46/93 y C48/93), Rec. 1996, I-1029

TJUE, Comisión/Luxemburgo (C-473/93), Rec. 1996, I-3207

TJUE, Familiapress (C-368/95), Rec. 1997, I-3689

TJUE, IN.CO.GE.'90 et al. (asuntos acumulados C-10/97 - C-22/97) Rec. 1998, I-6307

TJUE, Tanja Kreil (C-285/98), Rec. 2000, I-95

TJUE, Église de scientologie (54/99), Rec. 2000, I-1335

TJUE, Schmidberger (C-112/00), Rec. 2003, I-5659

TJUE, Omega (C-36/02), Rec. 2004, I-9609

TJUE, Viking (C-438/05), Rec. 2007, I-10779

TJUE, United Pan-Europe Communications Belgium et al. (C-250/06), Rec. 2007, I-11135

TJUE, Laval un Partneri (C-341/05), Rec. 2007, I-11767

TJUE, Dynamic Medien (C-244/06), Rec. 2008, I-505

TJUE, Gheorghe Jipa (33/07), Rec. 2008, I-5157

TJUE, Sabatauskas (C-239/07), Rec. 2008, I-7523

TJUE, Michaniki (C-213/07), Rec. 2008, I-9999

TJUE, Winner Wetten (C-409/06), 8 Septiembre 2010, Rec. 2010, I-0000

AG Maduro, Michaniki (C-213/07), Rec. 2008, I-9999

AG Kokott, Presidente del Consiglio (C-169/08), Rec. 2009, I-10821

b. Tribunales constitucionales nacionales y cortes supremas

i. Alemania

Sentenecia del Tribunal Constitucional Federal Alemán (STCF), tomo 37, p. 271 (1974) (Solange I)

STCF tomo 58, p. 1 (1981) (Eurocontrol)

STCF, tomo 73, p. 339 (1986) (Solange II).

STCF, tomo 89, p. 155 (1993) (Maastricht)

STCF tomo 92, p. 203 (1995) (EG-Fernsehrichtlinie)

STCF, tomo 102, p. 147 (2000) (Bananenmarktordnung)

STCF tomo 113, p. 273 (2005) (Europäischer Haftbefeh!)

STCF tomo 123, p. 267 (2009) (Lissabon) 
STCF, Decisión de 2/3/2010, Neue Juristische Wochenschrift (NJW) 2010, p. 833

STCF, Decisión de 6/7/2010, http://www.bverfg.de (Honeywel)

ii. Dinamarca

Corte Suprema Danés, Caso I 361/1997 de 6/4/1998, Europäische Grundrechtezeitschrift (EuGRZ) 1999, p. 49

iii. España

Tribunal Constitucional Español, Caso 1/2004 de 13/12/2004, Europarecht (EuR) 2005, p. 339

iv. Francia

Consejo Constitucional Francés, 2006-540 DC de 27/7/2006, Recueil des décisions 2006, p. 88

v. Irlanda

Crotty v. An Taoiseach, [1987] IR 173

Society for the Protection of Unborn Children (Ireland) Ltd. v. Grogan, [1989] IR 753

Attorney General v. X, [1992] 1 IR 1

vi. Italia

Corte Constitucionale Italiana, Caso 183/1973 de 18/12/1973 (FrontinI), Europäische Grundrechtezeitschrift (EuGRZ) 1975, p. 311

Corte Constitucionale Italiana, Caso 170/84 de 8/6/1984 (Granital), en: A. Oppenheimer, The Relationship between European Community Law and National Law, tomo I, 1994, p. 643

Corte Constitucionale Italiana, Caso 232/1989 de 13 resp. 21/4/1989 (Fragd), en: A. Oppenheimer, The Relationship between European Community Law and National Law, tomo I, 1994, p. 653

vii. Latvia

Tribunal Constitucional Letón, Caso 2008-35-01 de 7/4/2009, http://www.satv.tiesa.gov.lv

viii. Lituania

Tribunal Constitucional Lituano, asuntos acumulados 17/02, 24/02, 06/03, 22/04 de 14/3/2006, http://www.Irkt.It/dokumentai/2006/r060314.htm

ix. Polonia

Tribunal Constitucional Polaco, Caso K 18/04 de 11/5/2005, Europarecht (EuR) 2006, p. 236

Tribunal Constitucional Polaco, Caso Kp 3/08 de 18/2/2009, http://www.trybunal.gov.pl

x. República Checa

Tribunal Constitucional Czeco, Caso PI. ÚS 50/04 de 8/3/2006, http://www.concourt.cz

Tribunal Constitucional Czeco, Caso PI. ÚS 66/04 de 3/5/2006 
Tribunal Constitucional Czeco, Caso PI. ÚS 19/08 de 22/11/2008

Tribunal Constitucional Czeco, Caso PI. ÚS 29/09 de 3/11/2009, Europäische Grundrechtezeitschrift (EuGRZ) 2010, p. 209

A. Albi, Supremacy of EC Law in the Member States, Eur. Const. L. Rev. 3 (2007), p. 25

K. Alter, Establishing the Supremacy of European Law. The Making of an International Rule of Law in Europe, 2001.

A. Baylos Grau, El espacio supranacional de ejercicio des derecho de huelga y la restriccion de sus capacidades de acción, Rev. Der. Soc. 41 (2008), p. 123.

A. C. Becker, Vorrang versus Vorherrschaft, Europarecht (EuR) 2005, p. 353.

A. von Bogdandy/P. Cruz Villalón/P. M. Huber (eds.), Handbuch lus Publicum Europaeum, tomo I, 2007.

A. von Bogdandy/P. Cruz Villalón/P. M. Huber (eds.), Handbuch lus Publicum Europaeum, tomo II, 2008.

A. von Bogdandy/J. Bast (eds.), Europäisches Verfassungsrecht, 2ª ed. 2009.

A. von Bogdandy, Prinzipien der Rechtsfortbildung im europäischen Rechtsraum - Überlegungen zum Lissabon-Urteil des BVerfG, NJW 2010, p. 1 G. Bosco, La primauté du droit communautaire dans les ordres juridiques des Etats membres de l'Union européenne, en: O. Due/M. Lutter/J. Schwarze (eds.), Festschrift für Ulrich Everling, 1995, p. 149.

C. Calliess (ed.), Verfassungswandel im europäischen Staaten- und Verfassungsverbund, 2007.

M. Cartabia/B. de Witte/P. Pérez Tremps (eds.), Constitución europea y constituciones nacionales, 2005.

A. Celotto/T. Groppi, Diritto UE e diritto nazionale: Primauté vs controlimiti, Riv. ital. dir. pubb. Com. 14 (2004), p. 1309.

M. Claes, The National Courts' Mandate in the European Constitution, 2006

J. Combacau/S. Sur, Droit international public, 8 $8^{\mathrm{a}}$ ed. 2008.

T. von Danwitz, Europäisches Verwaltungsrecht, 2008.

E. Di Salvatore, L'identità costituzinale dell'Unione europea e degli Stati membri, 2008.

H. Dreier, en: H. Dreier, GG Kommentar, tomo III, 2ª ed. 2008, Art. 146 GG. 
A. Epiney, Zur Tragweite des Art. 10 EGV im Bereich der Außenbeziehungen, en: J. Bröhmer/R. Bieber/C. Calliess/C. Langenfeld/S. Weber/J. Wolf (eds.), Internationale Gemeinschaft und Menschenrechte, Festschrift für Georg Ress, 2005, p. 441.

U. Everling, Europas Zukunft unter der Kontrolle der nationalen Tribunal Constitucionale, EuR 2010, p. 91.

T. Giegerich, Europäische Verfassung und deutsche Verfassung im transnationalen Konstitutionalisierungsprozeß, 2003.

L. González Vaqué, El difícil equilibrio entre la libre circulación de mercancías y los derechos fundamentales en materia de libertad de expresión y de reunión: la sentencia "Schmidberger", Gaceta Jurídica de la U.E. y de la Competencia 227 (2003), p. 61.

C. Grewe/H. Ruiz Fabri, Droits constitutionnels européens, 1995.

D. Halberstam, Constitutional Hierarchy: The Centrality of Conflict in the European Union and the United States, in: J. L. Dunoff/J. Trachtman (eds.), Ruling the World? Constitutionalism, International Law, and Global Governance, 2009 , p. 326.

D. Halberstam/C. Möllers, The German Constitutional Court Says "Ja zu Deutschland!', German L. J. 10 (2009), p. 1241.

M. Hilf, Europäische Union und nationale Identität der Mitgliedstaaten, en: A. Randelzhofer/R. Scholz/D. Wilke (eds.), Gedächtnisschrift für Eberhard Grabitz, 1995, p. 163.

P. M. Huber, en: Sachs, GG Kommentar, 5aㅡ ed. 2008, Art. 146 GG.

W. Kahl, en: Calliess/Ruffert, EUV/EGV, 3a ed. 2007, Art. 10 EGV.

M. Kottmann/C. Wohlfahrt, Der gespaltene Wächter? - Demokratie, Verfassungsidentität und Integrationsverantwortung im Lissabon-Urteil, Zeitschrift für ausländisches öffentliches Recht und Völkerrecht (ZaöRV) 69 (2009), p. 443.

M. Kumm/V. Ferreres Comella, The Primacy Clause of the Constitutional Treaty and the Future of Constitutional Conflict in the European Union, Int'l J. Const. L. 3 (2005), p. 473.

M. Kumm, The Jurisprudence of Constitutional Conflict: Constitutional Supremacy in Europe before and after the Constitutional Treaty, Eur. L. J. 11 (2005), p. 262.

F. C. Mayer, Kompetenzüberschreitung und Letztbegründung, 2000.

M. Morlok, Selbstverständnis als Rechtskriterium, 1993. 
I. Pernice, Multilevel Constitutionalism in the European Union, Eur. L. Rev. 5 (2002), p. 511.

S. Pinon, L'effectivité de la primauté du droit communautaire sur la Constitution, Rev. Trim. Dr. Eur. 44 (2008), p. 263.

C. Richards, The Supremacy of Community Law before the French Constitutional Court, Eur. L. Rev. 31 (2006), p. 499.

W. Sadurski, 'Solange, chapter 3': Constitutional Courts in Central EuropeDemocracy-European Union, Eur. L. J. 14 (2008), p. 1.

C. Schönberger, Die Europäische Union als Bund, Archiv des öffentlichen Rechts (AöR) 129 (2004), p. 81.

C. Schönberger, Lisbon in Karlsruhe: Maastricht's Epigones at Sea, German L. J. 19 (2009), p. 1201.

E. Schmidt-Aßmann, Einleitung: Der Europäische Verwaltungsverbund und die Rolle des Europäischen Verwaltungsrechts, en: E. Schmidt-Aßmann/B. Schöndorf-Haubold, Der Europäische Verwaltungsverbund, 2005, p. 1.

M. N. Shaw, International Law, 6aㅡ ed. 2008.

A.-M. Slaughter/A. Sweet Stone/J. H. H. Weiler (eds.), The European Court and National Courts - Doctrine and Jurisprudence, 1998.

R. Streinz, en: Streinz, EUV/EGV, 2003, Art. 10 EGV.

C. Stumpf, en: Schwarze, EU-Kommentar, 2ª ed.. 2008, Art. 6 EUV.

J. P. Terhechte, Souveränität, Dynamik und Integration - making up the rules as we go along?, Europäische Zeitschrift für Wirtschaftsrecht (EuZW) 2009, p. 724.

A. Verdross/B. Simma, Universelles Völkerrecht, 3ª ed. 1984.

A. Voßkuhle, Der europäische Verfassungsverbund, Neue Zeitschrift für Verwaltungsrecht (NVwZ) 2010, p. 1.

R. Wahl, Europäisierung: Die miteinander verbundene Entwicklung von Rechtsordnungen als ganzen, en: H. H. Trute/T. Groß/H. C. Röhl/C. Möllers (eds.), Allgemeines Verwaltungsrecht - zur Tragfähigkeit eines Konzepts, 2008, p. 869.

R. Wahl, Die Schwebelage im Verhältnis von Europäischer Union und Mitgliedstaaten, Der Staat 48 (2010), p. 587.

A. Weber, Europäische Verfassungsvergleichung, 2010. 
A. Weber, Die Europäische Union unter Richtervorbehalt?, Juristenzeitung (JZ) 2010, p. 157.

A. Wille, Die Pflicht der Organe der Europäischen Gemeinschaft zur loyalen Zusammenarbeit mit den Mitgliedstaaten, 2003.

Recebido para publicação: 05/12/2011

Aceito para publicação: 23/12/2011 